\title{
Chapter 4 \\ South Sudanese Diaspora Children: \\ Contested Notions of Childhood, \\ Uprootedness, and Belonging Among \\ Young Refugees in the U.S.
}

\author{
Marisa O. Ensor
}

\section{South Sudanese Diaspora Children}

Chuol $^{1}$ turned 18 in June 2011, just 1 month before the independence of South Sudan, his native country, on 9th July. His 18th birthday signified Chuol's legal transition into adulthood in the United States where he now lives. On the other hand, the occasion would have been barely marked, if at all, in the small rural community where he was born, and where the categories "child," "youth," and "adult" are defined along cultural rather than chronological parameters. " "It is rough out there, but not like back in Africa, says my Mom." Chuol is responding to my query about life in Omaha, Nebraska, where I have been working with South Sudanese youngsters like him since 2009. Now in his early twenties, Chuol left war-torn South Sudan as an infant in 1992 when government soldiers from the north attacked their village. With Chuol on her back, his mother fled on foot to a crowded refugee camp in neighbouring Ethiopia. They arrived in the U.S. 3 years later. Having moved out of Africa when he was too young to remember it, Chuol's experiences growing up in the U.S. are illustrative of the complex processes of

\footnotetext{
${ }^{1}$ The names of all study participants have been changed to ensure their anonymity.

${ }^{2}$ Many people in South Sudan, especially in the rural areas, do not mark their chronological age. Asylum applications often list January 1st as the applicant's birthday. This is a random date assigned to all of those who cannot indicate their actual date of birth when first processed by the UN Refugee Agency (UNHCR), whose staff must also estimate people's age.
}

M.O. Ensor ( $\square)$

Georgetown University, Washington, DC, USA

e-mail: marisaensor@yahoo.com

M.O. Ensor

The International Institute for Child Rights and Development, Victoria, BC, Canada

(C) The Author(s) 2016

M.L. Seeberg and E.M. Goździak (eds.), Contested Childhoods:

Growing up in Migrancy, IMISCOE Research Series,

DOI 10.1007/978-3-319-44610-3_4 
inclusion and exclusion faced by thousands of South Sudanese-American children and youth.

Like Chuol and his mother, millions of refugees fled the south of Sudan during the Second Sudanese Civil War (1983-2005). They sought shelter in one of the sprawling camps in neighbouring Ethiopia, Kenya, Uganda, or else joined the urban poor in Khartoum or Cairo. The United Nations resettled nearly 31,000 refugees from these camps to the U.S. Many of them were children, often unaccompanied minors who had been orphaned or separated from their relatives during the war. In the 1990s, Omaha, Nebraska, emerged as an unlikely hub for these South Sudanese, both for primary resettlement from camps in Africa, and for secondary resettlement, as refugees placed in other States relocated to Nebraska in search of jobs, affordable housing and a sense of community. Currently, Omaha is home to approximately 10,000 South Sudanese refugees who, along with other displaced groups, represent over $1.7 \%$ of the city's total population. Mirroring demographic trends in their home country, the South Sudanese population in the U.S. is very young. Some of them arrived in the U.S. as refugees, as was the case with the close to four thousand famous "Lost Boys of Sudan" (HRW 1994) who were resettled to various American cities in 2001. Others are the U.S.-born children of refugee parents and have never lived in Africa.

The term "diasporas" is often used, both in Omaha and in South Sudan, to lump both groups together in everyday discourses. Many of these South Sudanese can indeed be seen as fulfilling all the criteria of a "refugee diaspora" (Van Hear 2009). That is, they are groups that are recently displaced due to conflict - or "a well-founded fear of persecution," in accordance with domestic and international legal standards ${ }^{3}$ - and that often maintain considerable material connections to the home state. Their life experiences have, on the other hand, often been quite diverse and disparate depending on their migratory trajectories, among other factors. Tensions and even violence among different migrant groups have recently intensified in Omaha, with some youth allegedly joining the many street gangs often composed of refugees and migrants of various nationalities that have sprung up in the area over the last decade.

Against this complex and tumultuous background, the diasporic identities and cultural practices of children and youth are being translated, appropriated, and creolized to fit into local social contexts and structures. Based on on-going

\footnotetext{
${ }^{3}$ The US definition of refugee derives from that established in the 1951 Convention relating to the Status of Refugees, as amended by the 1967 Protocol Relating to the Status of Refugees. More specifically, the US Immigration and Nationality Act defines "refugee" in Sect. 101(a)(42) as:

Any person who is outside any country of such person's nationality or, in the case of a person having no nationality, is outside any country in which such person last habitually resided, and who is unable or unwilling to return to, and is unable or unwilling to avail himself or herself of the protection of, that country because of persecution or a well-founded fear of persecution on account of race, religion, nationality, membership in a particular social group, or political opinion.
} 
ethnographic fieldwork conducted both in South Sudan and in the U.S. since 2009, this chapter examines the contested notions of "childhood," "migration" and "refugee-ness" that frame the experiences of South Sudanese-American children. This analysis seeks to elucidate the relationship between displacement, belonging and the construction of a diasporic sense of self among South Sudanese children growing up in migrancy in Omaha and, by qualified extension, elsewhere in the diaspora. The overarching argument made here is that the development of a sense of being part of a diaspora is frequently conditioned by complex and often violent processes of inclusion and exclusion that transcend fixed understandings of one's social, cultural and generational positioning. This is perhaps more the case for children and youth than for their adult counterparts.

Following this opening section, I present a brief discussion of the methods and conceptual frameworks that guided the research on which this chapter is based. More specifically, I situate the study of childhood and migrancy of South Sudanese refugees within the broader literature on diaspora studies, favouring notions of hybridity and multiple subjectivities. I then examine the historical and recent determinants underlying the arrival of South Sudanese refugees in Omaha, Nebraska, highlighting the geographical and cultural links between Africa and the U.S., past and present. A discussion of identity formation across generations, and issues of diaspora and violence allows me to contextualize the rise of street gangs as important spaces for the critical, if often violent, reinterpretation of fluid notions of identity, membership and belonging. In the concluding section, I suggest that, despite their troubled present and uncertain futures, young South Sudanese in Omaha display remarkable resilience and the ability to navigate multiple social loci in their struggle to adapt to challenging local conditions. As their experiences illustrate, understanding the hybrid affiliations that conform their identity formation is critical for a re-conceptualization of diaspora children as part of more than one geographically and socially located society. Simultaneously informing the scholarship on contested childhood(s) as fluid and situational, this perspective, I argue, allows for a more fruitful elucidation of the mechanisms of growing up in exile, and the broader urban refugee experience in Nebraska and elsewhere.

\section{Studying Diaspora Children: A Note on Frameworks and Methods}

A number of theoretical constructs have been developed over the years to examine the immigration experiences and the specific circumstances of migrant children (Ensor 2010). Traditional concern with geographical displacement in migrant and refugee population flows has tended to entail a fixation with "origins" and "homelands." The wider African diaspora, in particular, has provided an important site for the production of diasporic imaginaries. These range from a diffuse sense of identification with "blackness" to the appropriation of specific cultural productions, 
memories and political projects that stem primarily from diaspora movements in North America. This emphasis on African origins has led to a tendency to overlook differences in "black" cultures and ignore the continuities and discontinuities in the historical processes and conditions that have shaped Africans' experiences abroad (Patterson and Kelley 2000, 18).

Offering an alternative perspective, cultural theorist Hall (2003, 244) has postulated that diaspora identities are formed "with and through, not despite, difference; by hybridity... constantly producing and reproducing themselves anew, through transformation and difference" (original italics). This approach has also had particular currency in studies of youth and "second-generation" migrants who are especially likely to experience the "contradictory pulls" of cultural difference (Hall 2000, 232). The hybrid affiliations and creolized cultural practices of young people are indeed becoming a rather uncontroversial focus of the cultural studies literature (Ensor 2013a; Skrbiš et al. 2007, 263). Children and young people may be regarded as primarily representing the future of their societies of origin, the societies into which they or their parents have migrated (Ensor 2015), or their own presents and futures as autonomous, hybrid and transnational individuals. Diverging concerns may be reflected in different ideas and practices of childhood and negotiated in different social arenas.

The experiences of younger generations of South Sudanese in Omaha present a particularly good opportunity to bridge some of these analytical silos within diaspora studies. South Sudanese children, whose lifescapes encompass multiple geographically located societies, occupy fluid positionings characterized by both alienation from and affinity with not only the dominant "white" society, but also other "black" diaspora groups. Contesting rigid dichotomies separating children from adults, their experiences illustrate the contextual and relational nature of the definition of childhood as a social construct. They also exemplify the important relationship between migrancy as an attributed characteristic of children and their families (Näre 2013) on one hand, and differences in social position, migration trajectory and cultural practice on the other.

This chapter explores the production of complex and fluid diasporic identifications through an ongoing ethnographic study of the younger generations of South Sudanese in Omaha, NE, initiated in the summer of 2009. I interacted with members of the South Sudanese diaspora, both youngsters and adults, through my attendance at a variety of different events, such as academic conferences, social occasions and community celebrations, as well as more informal gatherings between younger South Sudanese and their non-South Sudanese friends. I also conducted in-depth, semi-structured interviews with fifteen youth (six females and nine males) whose ages ranged from 14 to 21 when the study began. These interviews took place in community centres, cafes and restaurants near participants' homes in different parts of Omaha. I used an interview guide aimed at eliciting reflections on younger people's experiences growing up in South Sudan or in exile, the challenges and opportunities of life in the U.S., and their hopes and expectations for their future. I interviewed the majority of my study participants at least two or three times, with interviews lasting for a variable length of time, typically around 
$2 \mathrm{~h}$. Furthermore, I have maintained close contact with some of these South Sudanese youngsters and their families, and have had regular updates on their activities and experiences. Their narratives, which simultaneously emphasize multiplicity, cross-cutting affiliations and overlapping identities, allow for a re-examination of prevalent assumptions in diaspora theory about the analytical distinction between "diaspora" and "host society."

\section{From Africa to Nebraska: Historical and Contemporary Factors}

Sudan, of which South Sudan was part until its secession on 9th July 2011, has long been a significant contributor to refugee movements globally (Tempany 2009). The two Sudanese Civil Wars-fought from 1955 to 1972 and 1983 to 2005-resulted in the deaths of an estimated two million people and caused massive internal and cross-border displacement. With over four million displaced during the Second Sudanese Civil War, the South Sudanese diaspora remains large in spite of the fact that at least 2.5 million South Sudanese returned to the country since 2005. Outside of Africa, the largest diaspora communities are in North America, Western Europe (UK, France, Italy, and Sweden), Australia and New Zealand, where there are an estimated 400,000-600,000 South Sudanese in total (The Hand Foundation 2014).

The South Sudanese refugees who found their way to the U.S. took a variety of paths. Some went to Khartoum to avoid the war, find work or go to school. However, for those who eventually reached Nebraska, the most common route was through the Itang refugee camp just across the border in neighbouring Ethiopia. This camp was managed by the UN Refugee Agency, the United Nations High Commissioner for Refugees (UNHCR). Many of these southerners "followed the trail of [human] bones eastward" (Hutchinson 1996, 6) to the relative safety of Ethiopian camps.

In the early 1990s, South Sudanese refugees' already precarious conditions in Ethiopia became untenable. Civil War and the overthrow of the regime of Haile Mengistu, who had ruled Ethiopia since deposing Emperor Haile Selassie in the 1970 s, caused the camps to be closed. At about the same time, news began to spread of refugee camps in Kenya, which offered an alternative place of safety, away from the deteriorating situation in Ethiopia and continuing troubles in their own country. For many of these refugees, the possibility of obtaining permission in the Kenyan camps to resettle in a third country such as the United States or Canada provided an additional reason to move to Kenya, where permission to re-locate was more likely to be given (Holtzman 2000, 21).

Where South Sudanese refugees initially resettled was generally not under their control. Those sponsored by relatives were sent to join their kin in the same community. For others, however, their placement was selected by resettlement agencies; the criteria used by the resettlement programmes were unknown by the 
refugees themselves. In early 1997, Nebraska came to be known among South Sudanese refugees as a "hot spot"- a place where many of them were contemplating relocating (Holtzman 2000, 37). They were attracted by cheap housing and employment opportunities in the meatpacking industry, a mainstay of immigrant labour. Their population was comprised mostly of very young people. Very few individuals were older than their mid-thirties, and the majority were considerably younger. Upon arrival in the U.S., they most commonly lived in young families, consisting of a husband, wife, and their young children. The younger refugees had little or no experience of South Sudan, having grown up in refugee camps or otherwise in exile. Their knowledge of the history and culture of their homeland mainly came through relayed information and experience from parents and other adults in the community (Poppitt and Frey 2007).

Adjustment to life in Nebraska has not been easy for many South Sudanese, who have faced a constellation of obstacles unusual in their depth and scope even for immigrants. There are vast differences in the lifestyles and values of Nebraska and South Sudan. Although some males - but hardly any females - had had at least brief experiences in African cities where they had gone to work or study, for most South Sudanese resettlement to the U.S. constituted their first significant stay outside of rural Africa. Most arrived largely unaware of American customs and without basic literacy skills or competence in English. For the large majority, even the most basic aspects of everyday living were completely unfamiliar. Beyond changes in daily routines, South Sudanese needed to re-forge their social worlds, which often proved to be an even more daunting task. The majority of the adult South Sudanese in my study describe their first years in America as "very difficult," "confusing" and even "frightening." Nevertheless, they also noted how relocation was filled with possibilities and hope for a better future. The experiences of these African-born refugees differ markedly from those of their U.S.-born children whose outlook is often less optimistic; they all counter the static notions of "community" and "enculturation" that still dominate prevalent understandings of diaspora.

\section{Identity Formation Across Generations}

In 2009 when I first met U.S.-born Biel and his then adolescent friends, I had just returned from a summer field trip to Rumbek, the capital of Lakes State in central South Sudan. The photographs I brought with me depicted scenes of the daily life of some of the tukul-dwelling (huts made of grass and mud), cattle-keeping, tall and proud-looking Dinka who constitute the largest ethnic group in the country. Biel and his friends are, however, Nuer. Chuol and most, but not all, of the South Sudanese I met in Omaha, are Nuer as well. Unusually tall agro-pastoralists like the Dinka, the Nuer represent the second largest ethnic group in South Sudan. As many members of the South Sudanese community in Omaha remarked, ethnic differences between Nuer, Dinka and other groups are, typically subsumed under generalizing labels such as "African," or "black" in the U.S.. The deadly pattern of revenge and 
counter-revenge attacks along Dinka-Nuer ethnic lines currently ravaging South Sudan on the other hand, have transformed ethnic divisions from a source of identity to a matter of life and death (Office of the Coordination of Humanitarian Affairs [OCHA] 2014). ${ }^{4}$

Accustomed to the completely urbanized life that frames the lifescapes of most American teenagers, Biel and his friends looked at my photographs with amused curiosity. Their repeated exclamations of "no way" and "not me" conveyed their lack of interest in ever adopting the traditional agro-pastoral livelihoods of their African counterparts. As one of them emphatically put it, "this is all very well for them; this is how they grow up. But this is not who I am. I have roots in the old country, but I was born here. I am an American." The large majority of South Sudanese children and adolescents living in Omaha today are U.S.-born and, in a legal sense, neither refugees nor migrants but American citizens. Their national identification and indeed their sense of personal identity are nevertheless often marked by tropes of displacement and non-belonging.

The development of a sense of identity is key to any discussion of diaspora groups. An examination of this process helps us to understand the ways in which South Sudanese diaspora members fit within the particular contours of contemporary American society. First-generation South Sudanese-Americans, as refugees who have fled their homes and lived in camps in Africa, do share problems and concerns with refugees in America from other countries and cultures. Because many are still dependent on welfare or belong to the class of the working poor, they also face many of the same problems that confront poor and working-poor, native-born Americans. South Sudanese identification with one group or the other - or neither-is often fluid and situational for both children and adults, as well as gender-differentiated.

The particular emotional landscape that South Sudanese children currently inhabit sharply contrasts with the conditions faced by their parents as first-generation migrants. Their perceptions of life in the U.S. follow the pattern predicted by Sluzki (1979) who concluded that many newly arrived immigrants experience a sense of euphoria, with high expectations and anticipated possibilities that may seem boundless. Energies are focused on attending to immediate needs, including finding jobs and a place to live. New immigrants had to establish themselves quickly, as all they received from the U.S. government was a loan for the plane ticket from Africa-which they had to start paying back within 6 months ${ }^{5}$ - less than three hundred dollars cash, and food stamps. In many of these

\footnotetext{
${ }^{4}$ In a document released on 9 January 2015, the Human Rights Division of the United Nations Mission in South Sudan (UNMISS) reported that there were reasonable grounds to believe that at least 353 civilians had been murdered and another 250 wounded in attacks in the capitals of the South Sudanese States of Unity and Jonglei between 15 April and 17 April of 2014. These attacks involved the deliberate targeting of victims on the basis of their ethnicity, nationality or perceived support for one of the parties to the conflict (UN News Centre 2015).

${ }^{5}$ Refugees traveling to the United States are issued loans by the International Organization for Migration (IOM) to pay for the costs of their transportation from overseas to the U.S. resettlement
} 
South Sudanese families, both spouses worked two shifts, encouraged both by need and by the prevalent belief that if they worked extremely hard for at least 5 years, they would prosper, which many did, at least in comparison to the living conditions they left behind in Africa.

With the new cultural and contextual norms of diaspora life, the public role of South Sudanese females quickly became significantly altered. Many women reported feeling isolated and even resented by their husbands and other males in the family as they assumed new more socially and economically active roles. Women were more readily able to find jobs as domestic workers, or as cleaners at hotels and restaurants; their husbands, on the other hand, with skills more suitable to an agrarian life in Africa than to urban America, remained trapped in menial low-paying jobs or unemployed and unable to provide for their families on their own. Today, marital tensions and even domestic violence are both common and much more frequently reported to the police than would have been the case in the homeland. Women, especially younger ones, are establishing themselves as community leaders, activists and breadwinners, challenging the old male leadership, and protesting against war, violence and racism (Lim 2009). Broad-ranging changes in daily life have brought major transformations not only in how women and men relate to each other, but also in how they see themselves as individuals and as members of their families and their community at large.

While refugee couples recognize that life in the U.S. sometimes requires a shift in gender responsibilities, new and widely-accepted norms concerning the gender division of labour have not emerged among first generation refugees. Instead, most have resorted to making adjustments and one-off changes as the need arises. As first-generation diaspora members often remark, there was far less ambiguity regarding social expectations for females and males, children and adults in South Sudan. In Omaha, it is the lack of well-defined roles, as much as the profound nature of the changes, which has caused tensions within South Sudanese families. The very definitions of childhood and adulthood - manhood and womanhood - are now surrounded by uncertainty, no longer clearly marked by rites of passage and initiation ceremonies.

Among some of the largest ethnic groups in South Sudan (i.e. the Nuer and the Dinka), the initiation of boys into adulthood is traditionally marked by facial scarification, with initiated young men expected to take on adult responsibilities. The Nuer receive facial markings (called gaar) of varying patterns. The most common initiation pattern among males consists of six parallel horizontal lines, which are cut across the forehead with a razor, often with a dip in the lines above the nose. Among the Dinka, initiation into manhood similarly involves the cutting of a varying number of parallel lines or V-shaped marks onto the forehead of the

(Footnote 5 continued)

sites and for various medical screening costs. The funds to cover the transportation are provided to IOM by the State Department's Bureau for Population, Migration and Refugees. A promissory note is signed by every refugee 18 years and older prior to arrival in the U.S. confirming the refugee's agreement to make regular monthly payments to the sponsoring agency (USCCB 2016). 
male initiate, called a parapool_-"one who has stopped milking”- as boys would no longer do the work of milking cows after initiation. Although far less common, young females may have their faces scarified as well amongst some Nuer and Dinka clans. In the case of females, scarification tends to be more a sign of high status than of initiation into adulthood and, especially among the Nuer, dotted patterns are preferred over deep cuts.

In South Sudan, current constructions of childhood for boys go beyond being non-initiated and include being single, not steadily employed, and still dependent on one's family (Jok 2005, 144-145). The fixed chronological parameters that define childhood and adulthood in the U.S. are seen as alien and confusing by some South Sudanese for whom social criteria and individual's behaviour are more reasonable predictors of one's generational position.

Racialized notions of belonging in or exclusion from other African diaspora groups constitute a further source of ambiguity, as affinity with other "black groups" has been undercut by experiences of racism. As numerous respondents observed, South Sudanese occupy a racially ambivalent position, 'labelled 'black' by the whites, but not really accepted by the black community." For many, the idea of "roots" and "origins" is an important aspect of their self-identity and their ability to "fit in." Aweng, a 17-year-old high school male student remarked:

Being Sudanese is pretty unique. The whole black culture here is dominated by African-Americans who don't know where their roots are... Nigeria, West Africa... African like me, but I am not really like them. And I still couldn't identify with them either. There are different types of Africans and no other African is like the South Sudanese, like me.

His comments illustrate the constant interplay between similarity and difference in the "black diaspora," and evidence the fundamental "instability and mutability of identities which are always unfinished, always being remade" (Gilroy 1993, xi).

Most migrants, especially those in contexts of forced migration like refugees, are required to move across discontinuous social spaces. These discontinuities can be markedly different for first and second-generation Americans. Migrancy and diaspora thus provide a particularly important context for redefining both childhood and inter-generational relations. Those African-born refugees who suffered traumatic experiences and severe conditions in their home country, and often also in transit and subsequently in the host country, harbour grievances and fears that may impact their relationship with younger generations (Vorrath 2012). Childhood memories of the homeland are often constructed through the language and imagery of violence, poverty and displacement, reinforced by media tropes of refugee-ness and war. Many nonetheless speak passionately about their pride in "being African," and praise the customs and traditions that regulated their pre-flight life in South Sudan.

Family or local tensions and conflict may result when parents' traditional attitudes and perceptions are dismissed or met with resentment from children and adolescents, who are often more acculturated than their parents in the new society through their greater access to schooling (Poppitt and Frey 2007). Some youngsters have, however, embraced their South Sudanese origins even if only vaguely familiar with their cultural meaning. Others have sought inclusion and belonging by 
joining youth groups and local South Sudanese community organizations which, in the hopeful words of Nyadhial, a very socially active and vivacious 15-year-old girl, can "make us proud of who we are, have events about the culture, where we are from, learn more about our history and what's going on in the country."

Riek, Nyadhial's older cousin, is also very politically engaged and has strong opinions about the resurgence of conflict in South Sudan, which he blames squarely on the lack of political will and the "shameful incompetence" of the country's leaders. He described himself as a "proud South Sudanese" and, unlike most of his compatriots, placed his national origins above his ethnic affiliation. As a child, his feelings about South Sudan were somewhat different, as he explained at one of our meetings at a small coffee shop near the church he attends on Sundays. His early memories of school revolved almost entirely around experiences of racism and feeling of exclusion and, as he became older, increasingly tense relationships with other groups of African descent. "White kids called us all 'blacks', but I look different, darker, taller, and felt different too. It was confusing and isolating. I think that it also made me ashamed to be South Sudanese," he explained.

Riek briefly joined a gang when he was in his mid-late teens, yielding to peer pressure, the lure of danger and adventure, and the promise of forging strong bonds of comradery with his South Sudanese "gang brothers." The harsh realities of life as a gang member, he admits, left him "empty and disappointed" and also "scared at how quickly things can go bad, very bad." Riek eventually left the gang and found a job at a local community newspaper. Other gang-affiliated youth find it harder to leave and, indeed, membership in street gangs has reportedly increased in Omaha in the last decade. Violence, both structural and physical, is a pervasive feature in the life of gang members.

\section{Diaspora, Violence and the Rise of Street Gangs}

South Sudanese diaspora children inhabit a cultural milieu where patterned inequalities shape social interactions. As is the case with other members of the African diaspora, South Sudanese socially-ascribed identity is largely racialized in homogenizing ways. Popular thinking in the Global North often equates common skin colour with an assumed common African behaviour, language, attitudes and capabilities (Ndhlovu 2009).

In addition to the obvious structural inequalities they face as the younger generation of a racialized minority, they are also targeted for what (De Vos and Suárez-Orozco 1990) have termed "psychological disparagement."

They become the object of symbolic violence, which stereotypes them as innately inferior (lazier, prone to crime, and so forth). These attributes make these disparaged minorities, in the eyes of the dominant society, less deserving of sharing in the society's dream and justifies their lot in life (Suárez-Orozco 2000, 211). 
Discrimination and racism are recurring themes discussed by many of the children and youth with whom I spoke. Inspired by the Longitudinal Immigrant Student Adaptation Study conducted by Carola and Marcelo Suárez-Orozco (Suárez-Orozco et al. 2007), I asked my study participants to complete the sentence, "Most Americans think that South Sudanese people are..." The following statements are representative of the kinds of responses I received:

Most Americans think that we are stupid.

Most Americans think that we are members of gangs.

Most Americans think that we are savages and violent.

Most Americans think that we are ignorant.

Most Americans think that we are primitive Africans.

Overwhelmingly, South Sudanese children reported a conviction that Americans had negative perceptions about them - a sentiment most vehemently expressed by boys and male teenagers. Their awareness of the prevailing ethos of hostility of the dominant culture could, at times, be ignored, internalized, or resisted, depending on personal and social circumstances. For most, these circumstances have recently become more hostile, owing, among other factors, to the rise of gang-related violence attributed to disenfranchised South Sudanese young boys. As the "ethos of reception" to South Sudanese diaspora members becomes less welcoming, their outlook on life's prospects has accordingly become dimmer. A prevailing ethos of hostility in the dominant culture makes it extremely difficult for migrant children to maintain an unblemished sense of self-worth (Suárez-Orozco 2000, 213). "Many are torn between the attachment to their parental culture of origin, the lure of the often more intrigued adolescent peer culture, as aspirations to join the American mainstream culture (which may or may not welcome them)" (ibid. 217).

A conflicted "ethos of reception" (Suárez-Orozco and Suárez-Orozco 2001) is often a significant determinant in diaspora life. The ensuing lack of communal trust frames ongoing relationships. It can also negatively impact the way that people in the host country perceive immigrants' homelands, and influence the manner in which children are taught about their own culture, history and other ethnicities or religions. In sum, it can add to the already significant stresses of growing up in migrancy.

Unlike their parents, most second-generation South Sudanese no longer perceive their circumstances in terms of a day-to-day struggle for survival. For them, disappointed hopes and aspirations coupled with a negative reception in the only community they know as "home" have at times led to feelings of distrust, anger, hostility and fear. Concern with violence is indeed a recurring theme that I have found among many of my study participants. Even if they were not personally exposed to the stresses and deprivations of war, all too many youngsters report having witnessed - and, in some cases, participated in - a disconcertingly high level of violence in their new neighbourhood and school settings. A distinction should be made between what might be called "hard" (physical) violence, and 
"soft" (psychological or symbolic) violence. While physical violence may be easier to identify, "the workings of psychic and symbolic violence are often more elusive but may be equally devastating in the long run" (Suárez-Orozco and Robben 2000, 1). As I have previously described:

Encounters with difference, dissonance, and exclusion are counterpoised by a search for new identity, social acceptance and belonging. Gang affiliation is one such effort which, while often associated with transgressive and even violent behaviour, must also be understood as an effort to respond to the many ruptures and transformations of anchors of belonging experienced by young refugees (Ensor 2014, 114).

Although Omaha has had its share of gang violence since the late 1980s, when the Bloods and Crips (two rival Los Angeles-based gangs) arrived to cash in on the emerging crack cocaine market, South Sudanese gangs are a newer phenomenon. By most accounts, the first ones-MJ, a Nuer acronym for "Dog Pussy," and African Pride - started operating in Omaha in 2004. Those that followed-MOB, GBLOCK, 402 (the area code for eastern Nebraska), South Sudan Soldiers, and TripSet-adopted equally colourful names. Some gangs include both Nuer and Dinka members, but ethnic segregation is more common. For instance, the "South Sudan Soldiers," a gang that has established a growing presence in the Omaha area since its founding in 2009, is made up almost exclusively of Nuer youth.

Most of my study participants agree that South Sudanese gangs in Omaha, which have no particular ideology guiding their actions, started not because of politics, drugs, or money, but out of boredom. The bulk of the members are young boys, aged fourteen to seventeen, although a few females reportedly also belong to some of the gangs. Predictably, most of them live in low-income neighbourhoods. Some gang members are believed to have dropped out of school to work so they could send money back to family members in Africa. Others, placed in public schools by their age rather than their typically lower grade level, quit discouraged by their poor performance in class and the derisive attitude of their more schooled classmates. Fights are common and have become more lethal as easily obtainable guns have replaced knives.

"The missing link is the parents," offered an adult South Sudanese male who moved to Omaha in 2003, "Nobody goes after their seventeen-year-old. They just think, 'We know what he's doing, he'll come back later'" (Massara 2010). He believed that lack of proper parental supervision constitutes a large part of the problem. As he admits, "I know a few families whose kids are the top ringleaders of the gang [and] they don't want to admit their kids are in a gang. It's not that they are defending the kids, they're just ignorant of what their kids are doing" (ibid.). His views on parents' responsibility for youngsters' misbehaviour is shared by a mother in her mid-thirties who noted, "In our community, a lot of parents don't know how to discipline their kids without using physical violence; that's what they grew up with" (ibid.). 
Ironically, together with Tunisia and Kenya, South Sudan is the third African state to establish full prohibition of corporal punishment for children ${ }^{6}$ (Santos 2011). Article 17 of the Transitional Constitution that came into force in 2011 establishes that "Every child has the right...to be free from corporal punishment and cruel and inhuman treatment by any person including parents, school administrations and other institutions." Caning and flogging remain, however, common approaches to child discipline. Furthermore, customary law still prescribes lashings as a suitable punishment for certain offenses committed by children (Ensor 2013b, 156). Proscriptions against the use of physical discipline for children continue to be perceived by many, both in South Sudan and in Omaha, as an ineffective and unjustified intrusion into parental roles. "That's when kids start to get in trouble, because they have no structure and no consequences to their actions," added the young mother (Massara 2010).

While gang-affiliated youngsters constitute only a fragment of the South Sudanese community in Omaha, their adversarial and occasionally violent efforts at self-affirmation have recently given rise to moral panics among local residents. Hardened attitudes towards "immigrants of colour" risk reinforcing patterns of xenophobia, exclusion and stigmatization (Suárez-Orozco 2000, 207). This trend is particularly worrisome for children growing up in immigrant communities for whom "[o]ptimistic hopes for the future are often tempered by pessimism borne of deprivation and disparagement" (ibid. 217).

\section{The Way Forward: New Waves of Displacement and Diasporization}

As Van Hear (1998) has posited, displaced groups in exile may go through various phases of re- or de-diasporization, often as a result of changing political circumstances in the homeland. This is particularly the case in conflict or crisis situations, where those abroad may become politically and economically mobilized on behalf of their troubled compatriots. Homeland conditions - and particularly the presence of political instability and conflict - may become important factors that frame the trajectory of diaspora groups, as well as the experiences of differently positioned children and adults within such communities.

Merely 2 years after its 2011 secession from Sudan, newly independent South Sudan plunged into a violent confrontation on 15 December 2013. The resurgence of conflict was triggered by bitter disagreements within the top leadership of the ruling Sudan People's Liberation Movement (SPLM), which splintered the party into several factions. The unabated violence has devastated the lives of millions of South Sudanese, uprooting nearly 2 million children, women and men. Nearly 1.5

\footnotetext{
${ }^{6}$ Also noteworthy, South Sudan ratified the UN Convention of the Rights of the Child on 5th May, 2015 , becoming the 195 th state to adopt the landmark child rights treaty.
} 
million people have been displaced internally, and another 480,000 have sought refuge in neighbouring countries (OCHA 2014). New diaspora communities are being formed in neighbouring African countries, while more established ones are again mobilizing to respond to the deteriorating local, regional and global conditions.

As a case in point, in early January 2014, a group of South Sudanese diaspora members in Omaha comprising Dinka, Nuer, and other ethnic groups (mainly Equatorians) voiced the need to discuss the on-going conflict in South Sudan. Those assembled denounced the ethnic violence with a unified South Sudanese-American voice. Despite their different ethnic affiliation and the on-going conflict back home, they re-affirmed their renewed commitment to working together through dialogue and mutual assistance. South Sudanese refugees in Omaha have long been involved in a range of activities aimed at promoting the development of their communities, both in the diaspora and in the homeland. Omaha was one of a handful of American cities that hosted voting sites for the referendum on South-Sudan's Independence of 9-15 January 2011. It saw the highest turnout in the United States with over three-thousand ballots cast. Prior to the recent resurgence of violence, some diasporas had chosen to return to their newly independent nation in order to launch small-scale philanthropic projects in and around their home villages, using resources and skills they had acquired in exile. Their actions illustrate the premise that, as circumstances become increasingly disjointed, diaspora members can experience a heightened emotional connection with their homeland. This encourages some to mobilize and increase their political involvement or give financial assistance to relatives or affiliated organizations (Vorrath 2012). Members of the youngest generation, often described as "the future of the nation," are at the frontline of these momentous developments (Ensor 2015, 47).

As the experiences of Chuol, Biel, Aweng, Nyadhial and Riek have illustrated, South Sudanese children are playing a pivotal role in many of the processes taking place in their societies. As is often the case in immigrant communities from war-torn nations where youngsters constitute the majority of the population, young people have played this role in both in their country of origin and their adopted nation. The diasporic identities of current generations of South Sudanese in Omaha are a product of multiple factors. These include historical memories and narratives, fluid and often contested constructions of childhood, shifting inter-generational and gender dynamics, changes in homeland politics, processes of repatriation, new waves of displacement and other global flows. These determinants should be examined alongside identity processes in the host society, including local vernacular discourses and racialized constructions of the African diaspora. Informed by the recent anti-essentialist shift in childhood studies, this chapter argues that children and youth's diasporic identities must always be understood as a product of a particular time and place.

Identity formation and the behaviours of South Sudanese children and youth in Omaha "conjure an image of a disempowered group facing its way to the centre" (Abdullah 2007, 25). Often referred to simply as "diasporas," regardless of their nationality status, their ascribed and self-identified situation of migrancy reflects a 
greater concern with social circumstances and cultural allegiances than with legal or geographical considerations. Their narratives at times invoke powerful sentiments of uprootedness and isolation intrinsically connected to exclusionary local constructions of South Sudanese-ness. They also illustrate their struggles to reassess their relationships to one another, and to re-forge cultural notions and expectations of childhood, family and community. The case of South Sudanese diaspora in Omaha thus exemplifies the need for studies of children and migrancy to recognize that the "birth of a community" in exile is not just an event confined to the early years of resettlement. Rather, it is an ongoing process that will continue into the future and will affect younger generations.

\section{References}

Abdullah, I. (2007). Youth culture and rebellion: Understanding Sierra Leone's wasted decade. Critical Arts: South-North Cultural and Media Studies, 16(2), 19-37.

De Vos, G., \& Suárez-Orozco, M. (1990). Status inequality: The self in culture. Newbury Park, CA: Sage Press.

Ensor, M. O. (2010). Understanding migrant children: Conceptualizations, approaches and issues. In M. O. Ensor \& E. M. Goździak (Eds.), Children and migration: At the crossroads of resiliency and vulnerability (pp. 15-36). Basingstoke, UK: Palgrave Macmillan.

Ensor, M. O. (2013a). Youth culture, refugee (re)integration, and diasporic identities in South Sudan. Postcolonial Text, 8(3), 1-19.

Ensor, M. O. (2013b). Participation under fire: Dilemmas of reintegration for child soldiers involved in South Sudan's armed conflict. Global Studies of Childhood Journal, 3(2), 153162.

Ensor, M. O. (2014). Crossing borders of geography and self: South Sudanese refugee youth Gangs in Egypt. In S. Spyrou, \& M. Christou (Eds.), Children and borders (pp. 114-128). London: Palgrave Macmillan.

Ensor, M. O. (2015). Heirs of the world's newest nation: Children as citizens and nation-builders in South Sudan. Global Studies of Childhood, 5(1), 47-58.

Gilroy, P. (1993). The black atlantic: Modernity and double consciousness. Cambridge, Massachusetts: Harvard University Press.

Hall, S. (2000). Conclusion: The multicultural question. In B. Hesse (Ed.), Unsettled multiculturalisms: Diasporas, entanglements, transruptions. London, New York: Zed Books.

Hall, S. (2003). Cultural identity and diaspora. In J. E. Braziel \& A. Mannur (Eds.), Theorizing diaspora. Malden, Oxford, Victoria: Blackwell Publishing.

Holtzman, J. D. (2000). Nuer journeys, Nuer lives: Sudanese refugees in Minnesota. Boston: Allyn \& Bacon.

Human Rights Watch, HRW. (1994). Sudan: The lost boys: Child soldiers and unaccompanied boys in Southern Sudan. Human Rights Watch, 6(10). Retrieved November 30, 2014 from https://www.hrw.org/sites/default/files/reports/sudan1994.pdf.

Hutchinson, S. (1996). Nuer dilemmas: Coping with war, money and the state. Berkeley: University of California Press. 
Jok, M. J. (2005). War, changing ethics and the position of youth in South Sudan. In J. Abbink \& I. van Kessel (Eds.), Vanguards or vandals: Youth, politics and conflict in Africa. Leiden: Brill.

Lim, S. (2009). "Loss of connections is death": Transnational family ties among Sudanese refugee families resettling in the United States. Journal of Cross-Cultural Psychology, 40(6), 1028 1040.

Massara, K. (2010). The gangs of Omaha: Sudanese who fled their war-torn country face growing violence in their ranks. Alertnet: Immigration. Retrieved January 10, 2015 from http://www. alternet.org/story/149106/the_gangs_of_omaha\%3A_sudanese_who_fled_their_war-torn_ country_face_growing_violence_in_their_ranks.

Näre, L. (2013). Migrancy, gender and social class in domestic labour and social care in Italy: An intersectional analysis of demand. Journal of Ethnic and Migration Studies, 39(4), 601-623.

Ndhlovu, F. (2009). The limitations of language and nationality as prime markers of African diaspora identities in the state of Victoria. African Identities, 7(1), 17-32.

Office for the Coordination of Humanitarian Affairs, OCHA. (2014). South Sudan crisis report. Retrieved November 10, 2014 from http://www.unocha.org/south-sudan/.

Patterson, T., \& Kelley, R. (2000). Unfinished migrations: Reflections on the African diaspora and the making of the modern world. African Studies Review, 43(1), 11-45.

Poppitt, G., \& Frey, R. (2007). Sudanese adolescent refugees: Acculturation and acculturative stress. Australian Journal of Guidance and Counselling, 17(2), 160-181.

Santos, P. M. (2011). South Sudan becomes 30th country to prohibit all forms of violence against children. In Office of the special representative of the secretary-general on violence against children. Retrieved November 12, 2014 from http://srsg.violenceagainstchildren.org/story/ 2011-07-29_374.

Skrbiš, Z., Baldassar, L., \& Poynting, S. (2007). Introduction-negotiating belonging: Migration and generations. Journal of Intercultural Studies, 28(3), 261-269.

Sluzki, C. (1979). Migration and family conflict. Family Process, 18(4), 379-390.

Suárez-Orozco, C., Suárez-Orozco, M., \& Todorova, I. (2007). Learning a new land: Immigrant students in American society. Cambridge, Massachusetts: Harvard University Press.

Suárez-Orozco, C., \& Suárez-Orozco, M. (2001). Children of immigration. Cambridge, Massachusetts: Harvard University Press.

Suárez-Orozco, C. (2000). Identities under siege: Immigration stress and social mirroring among the children of immigrants. In M. Suárez-Orozco, \& A. C. G. M. Robben (Eds.), Cultures under siege: Collective violence and trauma (pp. 194-226). Cambridge: Cambridge University Press.

Suárez-Orozco, M., \& Robben, A. C. G. M. (2000). Interdisciplinary perspectives on violence and trauma. In M. Suárez-Orozco, \& A. C. G. M. Robben (Eds.), Cultures under siege: Collective violence and trauma (pp. 1-41). Cambridge: Cambridge University Press.

Tempany, M. (2009). What research tells us about the mental health and psychosocial wellbeing of Sudanese refugees: A literature review. Transcultural Psychiatry, 46(2), 300-315.

The Hand Foundation. (2014). The helping hand: The South Sudanese diaspora. Retrieved January 12, 2015 from http://thehandfoundation.org/newsletter/2014/03/helping-hands-the-southsudanese-diaspora/.

United Nations News Centre. (2015). UN probe says South Sudan attacks 'nadir' of conflict marked by abuses, rights violations. Retrieved January 21, 2016 from http://www.un.org/apps/ news/story.asp?NewsID=49759\#.Vq5U5vkrKhf.

United States Conference of Catholic Bishops, UCCB. (2016). "Refugee travel loan collection." Retrieved January 21, 2016 from http://www.usccb.org/issues-and-action/human-life-anddignity/migrants-refugees-and-travelers/refugee-travel-loans-collection. 
Van Hear, N. (1998). New diasporas. The mass exodus, dispersal and regrouping of migrant communities. London: UCL Press.

Van Hear, N. (2009). The rise of refugee diasporas. Current History, 108(717), 180-185.

Vorrath, J. (2012). Engaging African diasporas for peace: Cornerstones for an emerging EU agenda. Paris: European Union Institute for Security Studies.

Open Access This chapter is licensed under the terms of the Creative Commons Attribution-NonCommercial 2.5 International License (http://creativecommons.org/licenses/by-nc/ $2.5 /$ ), which permits any noncommercial use, sharing, adaptation, distribution and reproduction in any medium or format, as long as you give appropriate credit to the original author(s) and the source, provide a link to the Creative Commons license and indicate if changes were made.

The images or other third party material in this chapter are included in the book's Creative Commons license, unless indicated otherwise in a credit line to the material. If material is not included in the book's Creative Commons license and your intended use is not permitted by statutory regulation or exceeds the permitted use, you will need to obtain permission directly from the copyright holder.

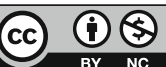

